\title{
Analysis of the expression profiles of cytokines and cytokine-related genes during the progression of breast cancer growth in mice
}

\author{
MI YOUNG JUNG ${ }^{1}$, SEUNG HYUN KIM ${ }^{1}$, DAEHO CHO ${ }^{2}$ and TAE SUNG KIM ${ }^{1}$ \\ ${ }^{1}$ Division of Life Sciences, School of Life Sciences and Biotechnology, Korea University, Seoul 136-701; \\ ${ }^{2}$ Department of Life Science, Sookmyung Women's University, Seoul 140-742, Korea
}

Received May 12, 2009; Accepted July 1, 2009

DOI: 10.3892/or_00000547

\begin{abstract}
Cytokines are a protein family of regulatory factors derived from tumors and their environmental components that contribute to the growth, invasion and metastasis of breast cancer. However, the way in which tumor progression and cytokines regulate each other is not well understood. In this study, we used an oligoDNA microarray to assess the kinetic expression profile of cytokine genes in tumor tissues and lymph nodes during the progression of tumor growth in mice that had been subcutaneously challenged with breast adenocarcinoma SB5b cells. Our results demonstrated that IL-15, IL-17, IL-18 and IL-18 binding protein (IL-18bp), which are associated with inflammation, were increased in tumor tissues. Conversely, chemokines and their receptors, including CXCR4/CXCL12, CCR7/CCL21, CCL9, CXCL9 and CCL12, were overexpressed in lymph nodes during tumor growth. Furthermore, RT-PCR and Western blot analysis revealed that IL-18, a pro-angiogenic factor in tumors, was up-regulated in tumor tissues. Interestingly, CCR3, IL-1R2, SOCS and IL-20 were up-regulated in tumor tissues, but down-regulated in lymph nodes during tumor growth. This result suggests that the expression of cytokines and cytokine-related genes was differentially regulated, which resulted in a beneficial effect for tumor progression.
\end{abstract}

\section{Introduction}

Breast cancer, which is the most common malignancy in women, is characterized by a distinct pattern of metastasis involving regional lymph nodes, bone marrow, the lungs and liver (1). In addition, progressive phenotypes such as tumor invasion and metastasis are currently the major causes of poor

Correspondence to: Dr Tae Sung Kim, Division of Life Sciences, School of Life Sciences and Biotechnology, Korea University, 5-ga, Anam-dong, Seongbuk-gu, Seoul 136-713, Korea

E-mail: tskim@korea.ac.kr

Key words: breast cancer, DNA microarray, cytokine, interleukin-18 prognosis in the treatment of breast cancer patients (2-4). However, it has recently been established that tumors are an ensemble product largely dependent on surrounding factors. Indeed, immune cells and stromal and vascular cells participate in the survival and progression of most solid tumors (5).

Cytokines, which are primarily secreted from immune cells, are important mediators that regulate the survival, growth, differentiation and effector function of cells (6). Although these molecules provide beneficial effects that lead to the elimination of tumor cells from the host, they can also enhance the growth of tumors in vivo (7). For example, cancer cells produce immunosuppressive cytokines such as transforming growth factor- $\beta 1$ (TGF- $\beta$ ), which can alter the characteristics of surrounding cells to create a favorable environment for the development of tumors and allow tumors to acquire immune evasion mechanisms (8). Furthermore, the secretion of chemokines in secondary lymphoid organs that are recruiting tumor cells are known to promote tumor invasion and metastasis $(9,10)$. Collectively, a variety of molecules form a network between tumor sites and lymphoid organs and their interplay is involved in the immune surveillance of tumor cells in the tumor-bearing host.

Over the last few years, several studies have been conducted using microarray to identify i) genes related to the metastases of primary breast tumors $(11)$, ii) genes expressed differentially between normal individuals and cancer patients (12) and iii) changes in the gene expression pattern before and after chemotherapy (13). However, no genome-wide studies conducted to date have been limited to cytokineassociated genes or designed to clarify the complex network and relationships of cytokines with tumor and immune cells.

Therefore, in the present study, we used oligoDNA microarray analysis to kinetically evaluate the expression profiles of cytokines, chemokines and their receptors at both tumor sites and regional lymph nodes using tumors grown in mice that were challenged with breast cancer SB5b cells injected subcutaneously into the mammary region. We found that the expression of some cytokines was regulated in a variety of patterns during the progression of tumor growth. These results may help expand our understanding of the roles that cytokines and chemokines play in the regulation of mammary carcinoma development. 
Table I. Primer sequences for PCR amplification.

\begin{tabular}{llll}
\hline Gene & \multicolumn{1}{c}{ Sense (5'-3') } & Antisense (5'-3') & Product (bp) \\
\hline$I L-10 R \beta$ & gaacctgactttcacagctc & gcccatgagtcataaatgtt & 315 \\
$I L-17$ & tccagaaggcctcagacta & agcatcttctcgaccctgaa & 239 \\
$I L-18 b p$ & gccactgtcttaactggaag & agaatgatgtgatactgggc & 374 \\
$I L-20$ & tggacagggtattcaaagtc & agttctcccaaagctttac & 223 \\
$C X C L 10$ & catggtcctgagacaaaagt & tgatgacacaagttcttcca & 412 \\
$C C R 3$ & attccatggactgaaagatg & aagaaagccattcatcaaga & 411 \\
$T G F-\beta 2$ & ccctagatttgacttgcac & gcccagtcactaagactctg & 335 \\
$G A P D H$ & acatcaagaaggtggtgaag & attcaagagagtagggaggg & 392 \\
\hline
\end{tabular}

bp, base pair.

\section{Materials and methods}

Cells and animals. SB5b cells were derived from an adenocarcinoma of the breast that arose spontaneously in a $\mathrm{C} 3 \mathrm{H} / \mathrm{He}$ mouse in our animal facility (14). The cells were maintained at $37^{\circ} \mathrm{C}$ in a humidified $5 \% \mathrm{CO}_{2}$ atmosphere in DMEM (Gibco BRL, Grand Island, NY) supplemented with $10 \%$ heat-inactivated fetal bovine serum (FBS, Biomeda, Foster City, CA) and antibiotics (100 units/ml penicillin and $100 \mu \mathrm{g} / \mathrm{ml}$ streptomycin, Gibco BRL). Eight to twelve-weekold pathogen-free $\mathrm{C} 3 \mathrm{H} / \mathrm{He}$ mice $\left(\mathrm{H}-2^{\mathrm{k}}\right)$ were obtained from Orient Bio (Kapyong, Korea) and maintained and treated under standard conditions according to the Animal Care Committee guidelines of Korea University.

Evaluation of tumor growth in vivo. $\mathrm{C} 3 \mathrm{H} / \mathrm{He}$ mice were injected subcutaneously into the right anterior mammary region with $0.2 \mathrm{ml}$ of a single-cell suspension that contained $1 \times 10^{5}$ of SB5b cells. The tumors that developed were then measured every 3 or 4 days using vernier calipers and the volumes were determined according to the formula: $\mathrm{V}=0.5$ $\mathrm{x} \mathrm{A} \mathrm{x} \mathrm{B}^{2}$, where $A$ is the largest dimension of the tumor and $B$ is the smallest dimension. The measured values were presented as the mean $\pm \mathrm{SD}$.

Cell preparation. At specified time points, tumor tissues from tumor-bearing mice (TBM) that were challenged with SB5b cells were removed and minced into $1-\mathrm{mm}$ pieces that were subsequently digested in a buffer containing $0.5 \mathrm{mg} / \mathrm{ml}$ collagenase type IV (Sigma, St. Louis, MO) and $0.05 \mathrm{mg} / \mathrm{ml}$ DNase (Sigma) for $6 \mathrm{~h}$ at room temperature. The resulting cells were then strained through a $70-\mu \mathrm{m}$ mesh to obtain a single cell suspension. In addition, lymph nodes were obtained from each stage of the TBM and then ground into single cells. The red blood cells (RBC) within both tissue cells were then lysed by incubation in RBC lysis buffer for $5 \mathrm{~min}$. The samples were then washed three times with DMEM-10\% FBS, after which the single cells were resuspended in DMEM-10\% FBS.

OligoDNA microarray analysis. An oligoDNA microarray (GenoCheck, Ansan, Korea) consisting of 141 mouse cytokinerelated genes was used to identify differentially expressed genes. This microarray is designed to identify control genes such as housekeeping genes and arabidopsis DNA. For target preparation, the total RNA was extracted from tumor tissues and regional lymph nodes of the TBM $(n=2-3 / g p)$ that had been challenged with SB5b breast cancer cells using TRIzol reagent (Sigma) according to the manufacturer's instructions. Total RNA from the SB5b cells and tissue from the lymph nodes of normal mice were used as control samples. The synthesis of fluorescence-labeled cDNA probes and hybridization processes were conducted using previously described methods (15). Following hybridization, the raw images from the microarray slides were analyzed using the software program, GenePix Pro 5.1 (Axon Instruments). For hierarchical clustering analysis of the gene expression profiles, we used the GeneSpring 6.1 program (Silicon Genetics, CA) and the Tree View program (http://www.microarrays.org/software). The results of the microarray analysis were confirmed by reverse transcription-polymerase chain reaction (RT-PCR).

RT-PCR analysis. Total RNA from either whole tumor tissues or regional lymph nodes was extracted using TRIzol reagent. cDNA was then synthesized from $1 \mu \mathrm{g}$ of total RNA in an Omniscript RT kit (Qiagen, Hilden, Germany). After cDNA synthesis, PCR amplification was conducted using an AccuPower PCR PreMix kit (Bioneer, Daejeon, Korea). The specific primers used to amplify each gene are listed in Table I. All PCR products were then electrophoresed on a $1.5 \%$ agarose gel.

Western blot analysis. For Western blot analysis, whole cell lysates were prepared, as previously described (16). Briefly, $100 \mu \mathrm{g}$ of each protein sample was separated on a $12 \%$ SDSpolyacrylamide gel and then transferred onto a nitrocellulose membrane. Next, the membrane was incubated in biotinylated rabbit anti-interleukin (IL)-18 antibody (RDI, Flanders, NJ), after which it was incubated in the presence of horseradish peroxidase-streptavidin. The protein level of the GAPDH (Santa Cruz, Santa Cruz, CA) was used as an internal loading control. Finally, the immuno-reactive bands were developed on X-ray film using an ECL Western Blotting Analysis System (Amersham, Buckinghamshire, UK) according to the manufacturer's instructions. 


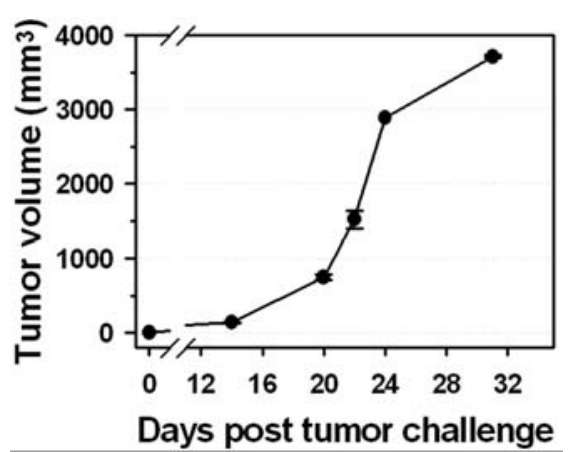

Figure 1. Tumor growth in $\mathrm{C} 3 \mathrm{H} / \mathrm{He}$ mice challenged with $\mathrm{SB} 5 \mathrm{~b}$ breast cancer cells. $\mathrm{C} 3 \mathrm{H} / \mathrm{He}$ mice were injected subcutaneously with $1 \times 10^{5} \mathrm{SB} 5 \mathrm{~b}$ tumor cells in the mammary fat pad region. The local tumor volumes were then determined as described in the Materials and methods section.

Table II. Up- or down-regulated genes in tumor tissues during tumor progression.

\begin{tabular}{lccccc}
\hline & \multicolumn{5}{c}{ Ratio (tumor tissue/SB5b cells) } \\
\cline { 2 - 6 } Gene symbol & Stage 1 & Stage 2 & Stage 3 & Stage 4 & Stage 5 \\
\hline Up-regulation & & & & & \\
CCR3 & 1.34 & 1.46 & 2.13 & 2.32 & 3.31 \\
$I L-18 b p$ & 1.27 & 1.48 & 2.60 & 2.89 & 2.85 \\
$I L-18$ & 1.24 & 1.20 & 1.78 & 1.75 & 2.04 \\
$I L-15$ & 1.29 & 1.30 & 1.50 & 1.54 & 1.62 \\
$I L-17$ & 1.77 & 1.92 & 2.15 & 1.29 & 1.75 \\
$C X C L 11$ & 1.33 & 2.56 & 1.11 & 1.05 & 1.12 \\
$I L-1 R 2$ & 1.20 & 1.49 & 2.19 & 2.05 & 1.30 \\
$I L-20$ & 1.68 & 1.44 & 1.69 & 1.62 & 1.82 \\
SOCS3 & 1.51 & 1.95 & 1.87 & 1.45 & 1.63 \\
Down-regulation & & & & & \\
$I L-19$ & 0.45 & 0.38 & 0.45 & 0.37 & 0.45 \\
TGF 32 & 0.76 & 0.53 & 0.53 & 0.50 & 0.71 \\
\hline
\end{tabular}

\section{Results}

Establishment of an in vivo breast cancer mouse model with SB5b cells. To establish an in vivo mouse model of breast cancer, we injected SB5b breast carcinoma cells subcutaneously into $\mathrm{C} 3 \mathrm{H} / \mathrm{He}$ mice. The mice were then evaluated for the formation of a tumor every 3 or 4 days. Ten days after challenge with the SB5b cells, a local tumor was initially observed in the anterior mammary region of the mice. As shown in Fig. 1, the tumor growth developed rapidly between days 20 and 24 after the tumor injection. For kinetic analysis of the cytokine profiles during tumor progression, we divided the progress grade of the TBM into 5 stages according to the size of the tumor (stage 1-stage 5).

Expression profiles of cytokine-related genes in breast tumor tissues and lymph nodes of TBM. To evaluate the expression pattern of cytokine-related genes during the progression of breast cancer, tumor tissues and regional lymph nodes were
Table III. Up- or down-regulated genes in lymph nodes during tumor progression.

\begin{tabular}{|c|c|c|c|}
\hline \multirow[b]{2}{*}{ Gene symbol } & \multicolumn{3}{|c|}{ Ratio (TBM-lymph node/normal lymph node) } \\
\hline & Stage 1 & Stage 3 & Stage 5 \\
\hline \multicolumn{4}{|l|}{ Up-regulation } \\
\hline$I L-18 b p$ & 0.98 & 1.84 & 3.18 \\
\hline CCL12 & N.D & 1.35 & 2.41 \\
\hline CCL9 & 0.93 & 1.35 & 2.04 \\
\hline CXCL9 & 0.94 & 1.55 & 1.96 \\
\hline$I L-10 R \beta$ & 0.88 & 1.70 & 1.93 \\
\hline CXCR4 & 1.16 & 1.39 & 1.92 \\
\hline STAT1 & 0.96 & 1.57 & 1.91 \\
\hline$C C R 7$ & 1.01 & 1.74 & 1.88 \\
\hline $\operatorname{IRF} 1$ & 0.88 & 1.55 & 1.64 \\
\hline IRF4 & 0.90 & 1.63 & 1.63 \\
\hline$I F N-\alpha R I$ & 1.05 & 1.44 & 1.61 \\
\hline CXCL12 & 0.89 & 1.68 & 1.57 \\
\hline$J A K 1$ & 0.94 & 1.56 & 1.59 \\
\hline NFATcl & 1.01 & 1.52 & 1.56 \\
\hline \multicolumn{4}{|c|}{ Down-regulation } \\
\hline$C C R 3$ & 0.83 & 0.26 & 0.26 \\
\hline$I L-20$ & 1.20 & 0.31 & 0.27 \\
\hline CXCL5 & 1.19 & 0.33 & 0.31 \\
\hline$T N F-\alpha S F 1 \beta$ & 1.09 & 0.41 & 0.33 \\
\hline SOCS5 & 1.09 & 0.53 & 0.41 \\
\hline$I L-24$ & 1.33 & 0.51 & 0.48 \\
\hline$I L-23$ & 1.03 & 0.58 & 0.51 \\
\hline$I L-6$ & 0.83 & 0.57 & 0.57 \\
\hline$J A K 3$ & 1.05 & 0.59 & 0.61 \\
\hline CSF3 & 1.02 & 0.39 & 0.63 \\
\hline INHA & 0.78 & N.D & 0.66 \\
\hline$I L-21$ & 1.22 & 1.10 & 0.68 \\
\hline NFATc3 & 1.29 & 0.82 & 0.68 \\
\hline$I L-1 R 2$ & 1.15 & 0.26 & 1.07 \\
\hline
\end{tabular}

N.D, not determined.

freshly isolated from TBM during each stage. A mouse 141 cytokine microarray was then used to generate the gene profiles of tumors collected from both sites, which were subsequently evaluated by comparison with those from SB5b cells in culture or lymph node cells from normal mice.

Of the detectable genes, many were found to be up- or down-regulated in either the tumor tissues or lymph nodes of the mice with breast cancer. For example, cytokine genes such as IL-15, IL-17 and IL-18 were up-regulated, while IL-19 was down-regulated in tumor tissues during the progression period (Fig. 2 and Table II). Conversely, genes such as CCL12, CCL9, CXCL5 and IL-24 were only up- or down-regulated in the TBM lymph node cells (Fig. 3 and Table III). However, some genes were differentially expressed in samples from both sites. For example, the CCR3, IL-1R2 and IL-20 genes were 

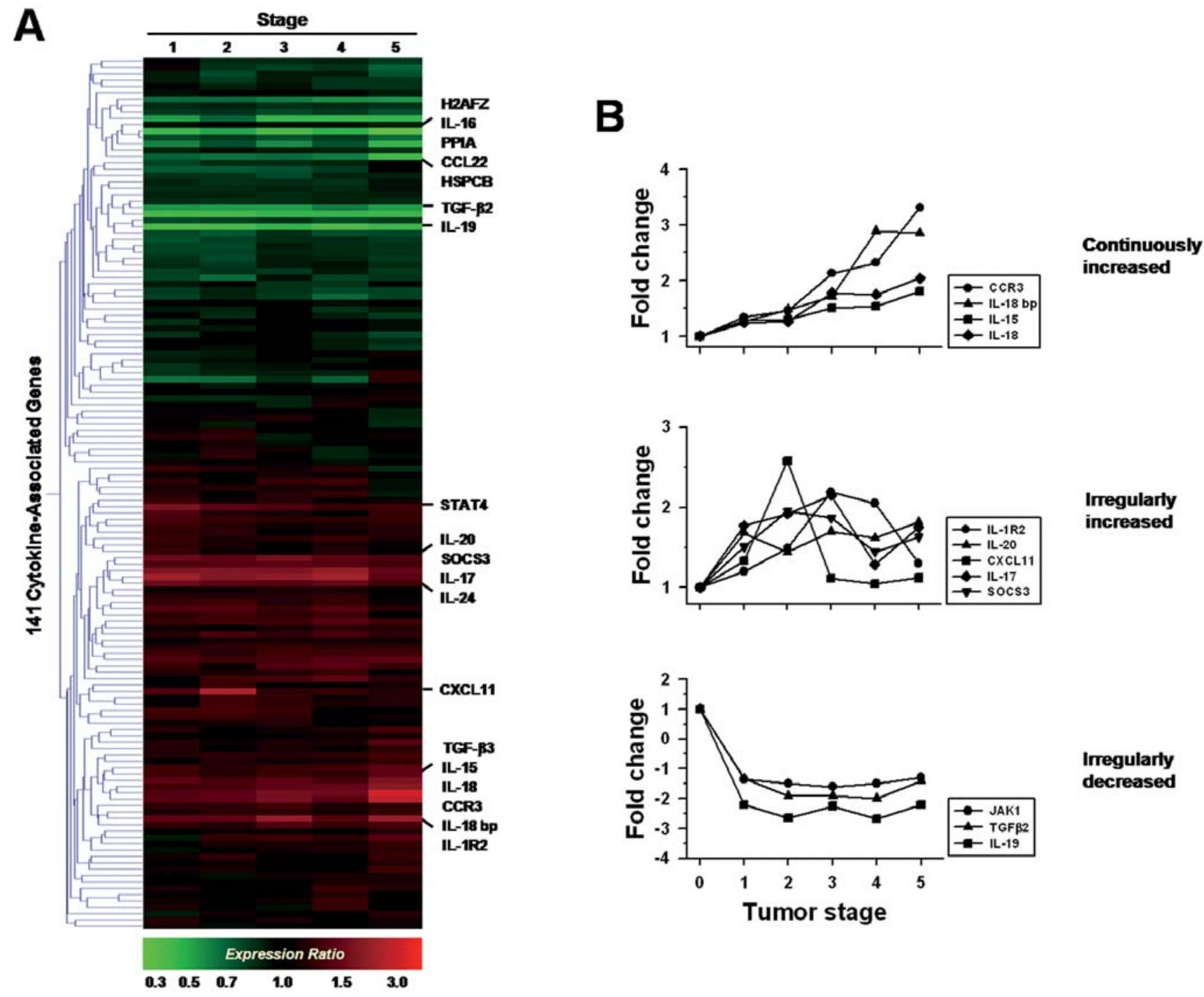

increased

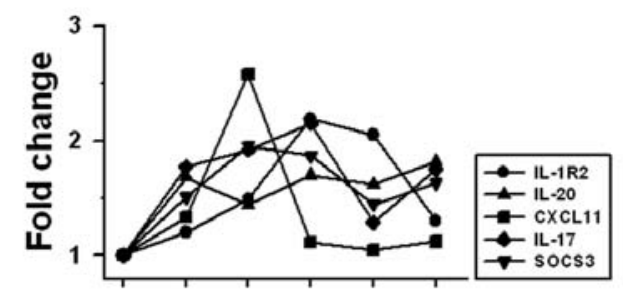

Irregularty

increased

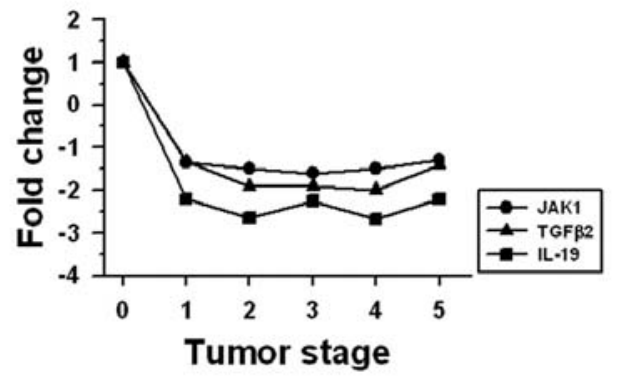

Irregularty

decreased

Figure 2. Hierarchical clustering analysis and line plots of altered genes in the tumor tissues from TBM. (A) Expression profiles of cytokine-associated genes were obtained using an oligoDNA microarray harboring 141 DNA probes (columns). The fold ratio of gene expression values are represented by colors, with red representing overexpression and green representing down-regulation as compared to SB5b breast cancer cells. Two dimensional hierarchical clusters were prepared on the basis of the gene expression profiles of each sample using the GeneSpring 6.1 and Gene Tree View software packages. (B) Line plots were depicted based on genes that were up-/down-regulated by $>1.5$-fold. Genes were divided into continuously, irregularly up- or down-regulated patterns. There were no important cytokine-related genes that were continuously down-regulated.

up-regulated in tumor tissue cells, but down-regulated in lymph node cells. Interestingly, as the breast tumors grew in mice, the mRNA expression of IL-18bp increased remarkably in both the tumor and lymph node cells.

To confirm the data generated by the cytokine microarray analysis, we conducted RT-PCR using primers specific for the selected genes. As shown in Fig. 4, similar to the results from the microarray analysis, the mRNA of CCR3 and IL18bp in tumor tissues from each stage of growth was up-regulated, while that of TGF- 32 was down-regulated when compared to the controls. However, we found that the expression pattern of CCR3 in tumor tissues did not correspond to that of the microarray analysis, in which they were up-regulated by $>3$-fold during the late stages of tumor progression. Moreover, when RT-PCR analysis was conducted using lymph node samples from each stage, we found that the expression patterns of IL-10Rß, IL-18bp, CCL12 and CXCL10 were similar to those observed in the microarray analysis.
Increased expression levels of IL-18 in tumor tissue cells. In some clinical studies, patients with breast carcinoma showed higher levels of serum IL-18 than their normal counterpart subjects (3). In addition, the serum IL-18 levels were also significantly higher in patients suffering from a metastatic breast tumor when compared to non-metastatic patients, which suggests that there is a possible correlation between the level of IL-18 and malignant risk in patients with breast cancer (17). Therefore, based on the results of previous studies and those of the microarray analysis conducted in the present study, we investigated the expression level of IL-18 in tumor tissues. When RT-PCR analysis was conducted, we observed an increased level of IL-18 transcripts that corresponded to the stages of tumor progression and agreed with the results of the cytokine microarray analysis (Fig. 5A). Next, ELISA was conducted to determine the amount of IL-18 secreted from primary cultures of tumor tissue cells; however, no IL-18 was detected. Because it was possible that the secretion of IL-18 

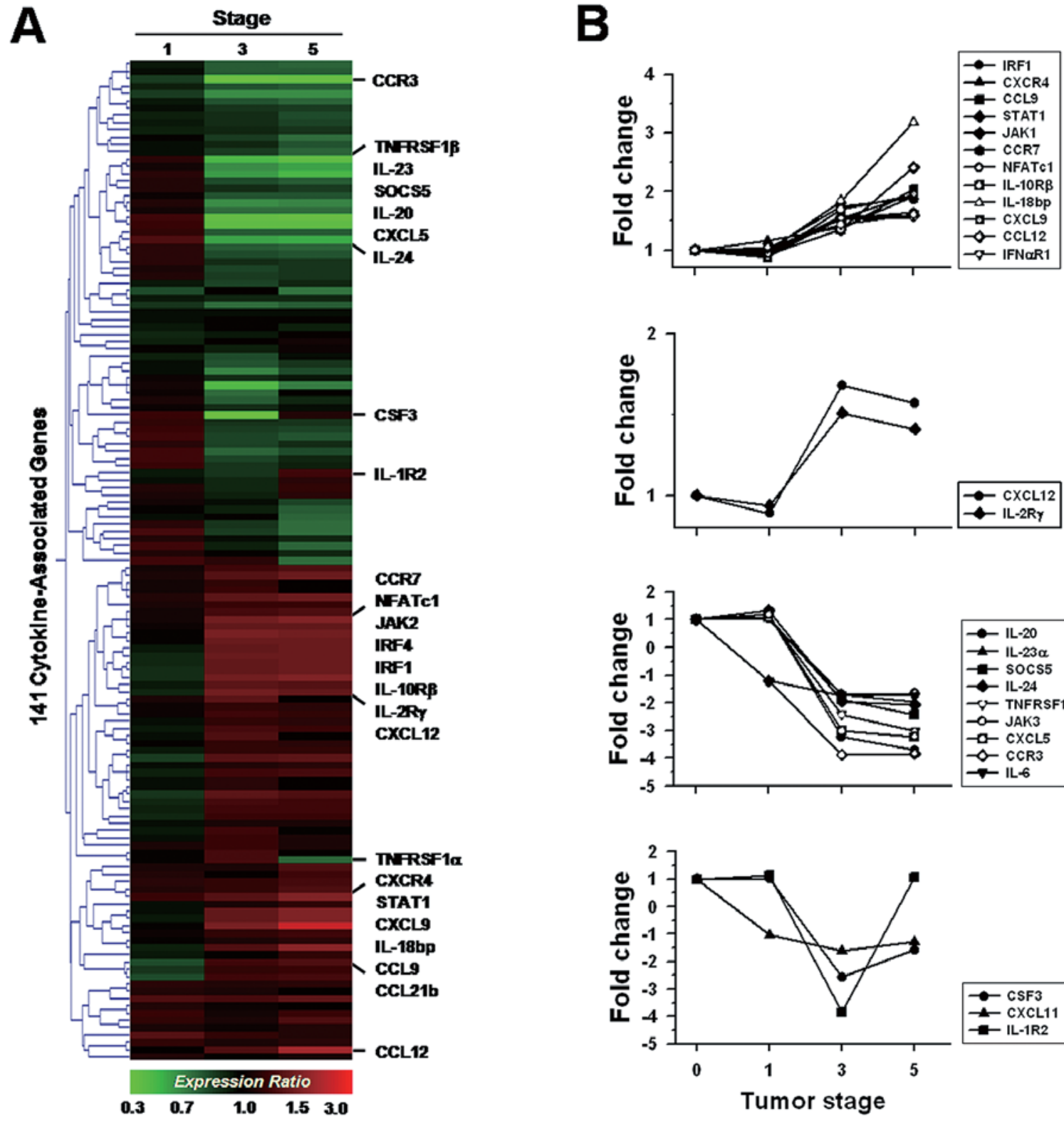

\section{Continuously increased}

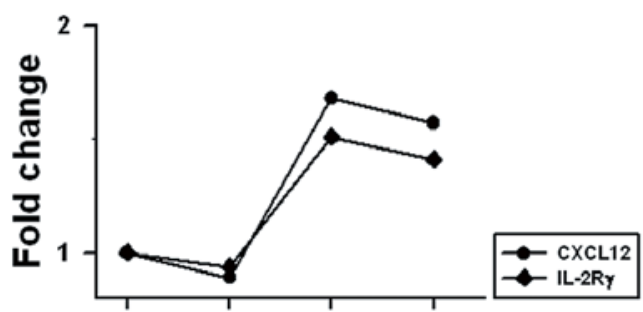

\section{Irregularty increased}

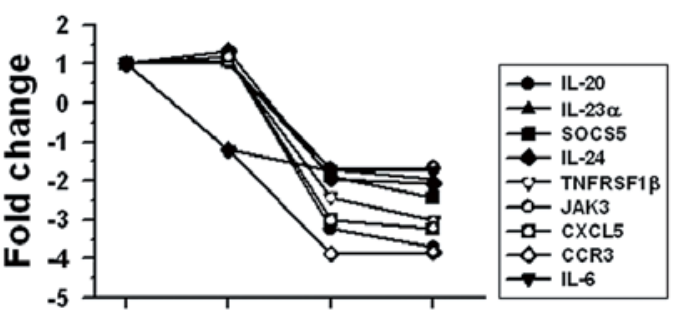

Continuously decreased

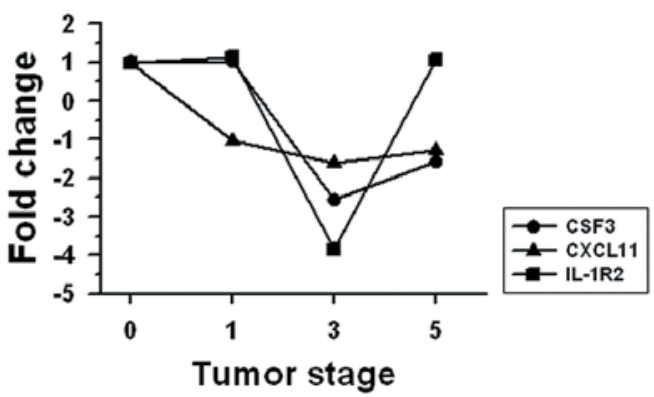

Irregularty decreased

Figure 3. Hierarchical clustering analysis and line plots of altered genes in the regional lymph nodes obtained from TBM. (A) Expression profiles of cytokineassociated genes were obtained using an oligoDNA microarray harboring 141 DNA probes (columns). The fold ratio of gene expression values are represented by colors, with red representing overexpression and green representing down-regulation as compared to the lymph nodes of normal mice. Two dimensional hierarchical clusters were prepared on the basis of the gene expression profiles of each sample using the GeneSpring 6.1 and Gene Tree View software packages. (B) Line plots were depicted based on genes that were up-/down-regulated by $>1.5$-fold. Genes were divided into continuously, irregularly up or down-regulated patterns.

or the sensitivity of the antibody used was too low to allow detection, we evaluated the whole cell lysates from the tumor mass for the presence of IL-18 by Western blot analysis. The results of the Western blot analysis revealed that both the active $(18 \mathrm{kDa})$ and the inactive forms $(24 \mathrm{kDa})$ of IL-18 protein increased as a function of tumor growth (Fig. 5B).

\section{Discussion}

The local cytokine/chemokine milieu generated by the tumor microenvironment is important for the growth, metastasis and immune evasion of breast tumors. Cytokines, which regulate the survival, growth, differentiation and effector response of innate and acquired cellular immunities (7), are primarily secreted by mononuclear phagocytes and activated $\mathrm{T}$ lymphocytes, although they are also produced by cancer cells.
In the present study, we evaluated the cytokine-related gene expression pattern generated by tumor cells and lymph node cells during the development of breast cancer. Our results revealed that their expression was commonly and differentially regulated in the tumor and lymph node sites during the progression of tumor growth.

IL-18 and its natural inhibitor, IL-18bp, were remarkably up-regulated in tumor tissue cells (Fig. 2 and Table II). IL-18, which was originally identified as interferon- $\gamma$-inducing factor, is a pro-inflammatory cytokine that regulates the Th1 response and inhibits angiogenesis (18). Due to its antineoplastic properties, IL-18 has been proposed for use as a novel adjuvant to treat cancer (19). However, previous studies have shown that IL-18 also exerts favorable effects on tumor progression (2-4). For example, Kim et al and Park et al reported that IL-18 mediates the angiogenesis of tumors via a 

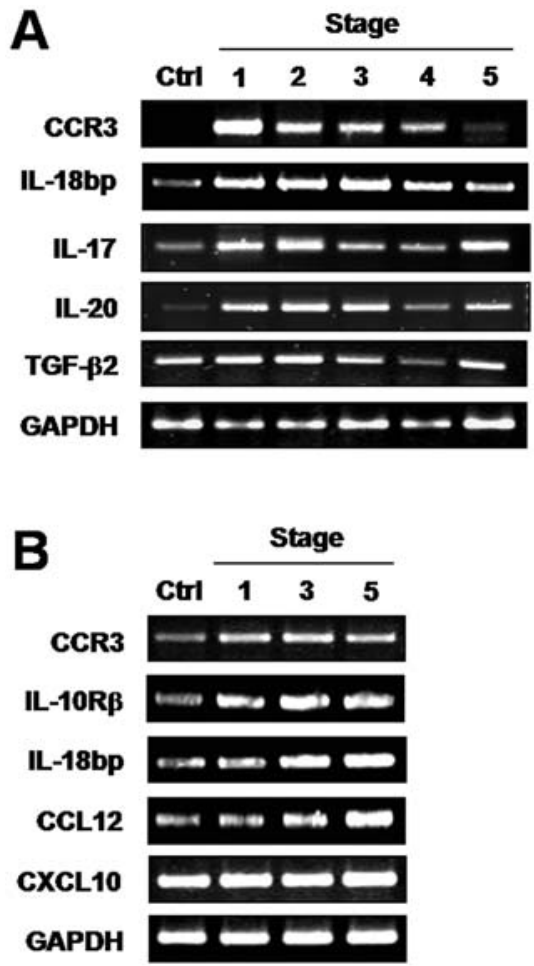

Figure 4. Verification of the differentially regulated genes by RT-PCR of tumor tissues (A) and lymph nodes (B). Total RNA was prepared from samples obtained during each stage of tumor growth and the mRNA expression of the selected genes was then analyzed by RT-PCR. The PCR products were then separated on a $1.5 \%$ agarose gel.

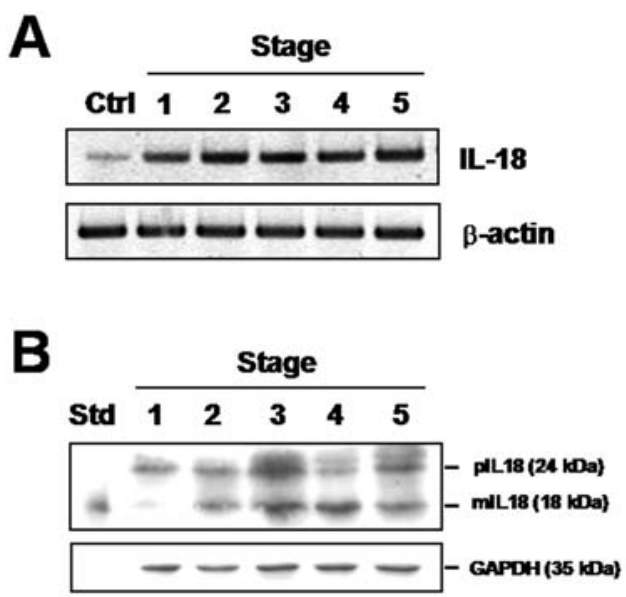

Figure 5. Expression of IL-18 by tumor tissues. (A) mRNA expression of IL-18 was assessed by RT-PCR. (B) Whole cell lysate from samples collected during each stage of tumor growth was loaded onto an SDS-PAGE gel to determine the expression of IL-18 by Western blot analysis. GAPDH was used as an internal control and recombinant IL-18 was used as a positive control.

mutual stimulation between this cytokine and vascular endothelial growth factor $(20,21)$. Some studies have also suggested that IL-18 stimulates migration of tumor cells in a matrix metalloproteinase-dependent manner $(22,23)$. Moreover, several studies have demonstrated that IL-18 can enable tumors to survive from attacks by immune cells $(24,25)$. The remarkable induction of IL-18 in tumor tissues is in agreement with the results of former studies, which indicate that it may contribute to tumor growth, survival and escape from immune surveillance. Although increased levels of IL-18 and IL-18bp were detected in this study, no changes in the IFN- $\gamma$ levels were observed during any stage of tumor development (Fig. 2A and Table II). However, further studies must be conducted to elucidate the reason for the absence of changes in IFN- $\gamma$ expression in this study. The levels of IRF-1, which acts as a tumor suppressor, were slightly higher in the lymph nodes of mice with cancer (Fig. 3 and Table III). The anti-tumor activity of IFN- $\gamma$ is mediated in part through IFN regulatory factor-1 (IRF-1); therefore, its production may have been blocked by IRF-2 (26).

Among the genes that were down-regulated in tumor tissues, TGF- $\beta$ is one of the most prominent (Fig. 3 and Table III). Indeed, TGF- $\beta$ is known to exert biphasic effects by acting as a tumor suppressor during the early stages of cancer, but by promoting invasion and metastasis during later stages (27). In the case of our breast cancer model, it appears that TGF- $\beta$ exerts a growth-inhibitory response against cells obtained from tumors during the early stages of development, which suppresses further progression of the tumor. However, during later stages, as the tumor grows rapidly, the tumor environment overpowers the suppressive function of TGF- $B$. Indeed, as shown in Fig. 2, the levels of another isoform of TGF- $\beta$, TGF- 33 , were slightly higher during the later stages of tumor development. Therefore, it is possible that this isoform promotes tumor growth.

The expression patterns of both chemokine receptors and their ligands are generally correlated with the invasion and metastasis of tumor cells because their specific interaction modulates the numbers and types of infiltrating cells within the tumor site. The two chemokine receptor-chemokine pairs, CCR7-CCL19/CCL21 and CXCR4-CXCL12, were overexpressed in lymph nodes in this model (Fig. 3). CCL19 and CCL21 are strong chemotactic factors for dendritic cells (DCs). CCR7-positive mature DCs enter lymph nodes, where they link the innate and adaptive immunity through interactions between the T cells and DCs. Together, CCR7 and its ligands, CCL19 and CCL21, initiate the immune system response to tumor growth. In addition, CCR7-CCL21 plays a key role in the migration of tumor cells into the sentinel lymph nodes (28). In the present study, CXCR4-CXCL12 was up-regulated >2-fold (Table III). CXCR4 and its ligand, CXCL12, are known to be expressed in a variety of tissues in which mammary carcinoma cells preferentially metastasize including lymph nodes, bone marrow and lung tissue $(1,9,29)$. The gradient concentration of CCL21 or CXCL12 in lymph nodes provides the migration cue to tumor cells expressing cognate receptors, which may help the tumors metastasize to other organs. In this study, CCL9 and CCL12, which are also considered to assist in tumor development, were significantly up-regulated (Fig. 3 and Table III); however, there is little information regarding the roles that these cytokines play. CXCL11 peaked during the initial stages of tumor development and then decreased, while CXCL9 was increased consistently in lymph nodes (Figs. 2 and 3; Tables II and III). CXCL9 and CXCL11 are known to be interferon-inducible chemokines that also have angiostatic activity. Specifically, CXCL9 and CXCL11 inhibit tumor growth and metastasis via a decrease in tumor-associated angiogenesis (30). 
In this study, we generated an expression profile of cytokine-associated genes kinetically for both the primary tumor site and the lymphoid organ during the development of breast cancer. We found that a large complex network of cytokines and chemokines was involved in the development of breast cancer. In general, the number and expressional variation of regulated genes was greater in the lymph nodes than at the tumor site. Although cytokines such as IL-18, TGF-B, IRF-1, CXCL9 and CXCL11 generally suppress tumors, they exert unfavorable effects on the host immune system as the tumor progresses. Our results may provide insight into the role that cytokines play in the malignant progression of breast tumors. However, further study is necessary to define their specific roles.

\section{Acknowledgements}

This study was supported by a grant of the Science Research Center Program, Ministry of Science and Technology, Republic of Korea (R11-2005-017).

\section{References}

1. Dewan MZ, Ahmed S, Iwasaki Y, Ohba K, Toi M and Yamamoto N: Stromal cell-derived factor-1 and CXCR4 receptor interaction in tumor growth and metastasis of breast cancer. Biomed Pharmacother 60: 273-276, 2006.

2. Eissa SA, Zaki SA, El-Maghraby SM and Kadry DY: Importance of serum IL-18 and RANTES as markers for breast carcinoma progression. J Egypt Natl Cancer Inst 17: 51-55, 2005.

3. Günel N, Coskun U, Sancak B, Günel U, Hasdemir O and Bozkurt S: Clinical importance of serum interleukin-18 and nitric oxide activities in breast carcinoma patients. Cancer 95: 663-667, 2002.

4. Merendino RA, Gangemi S, Ruello A, Bene A, Losi E, Lonbardo G and Purello-Dambrosio F: Serum levels of interleukin-18 and sICAM-1 in patients affected by breast cancer: preliminary considerations. Int J Biol Markers 16: 126129, 2001.

5. Joyce JA: Therapeutic targeting of the tumor microenvironment. Cancer Cell 7: 513-520, 2005.

6. Heinrich PC, Behrmann I, Muller-Newen G, Schaper F and Graeve L: Interleukin-6-type cytokine signaling through the gp130/Jak/STAT pathway. Biochem J 334: 297-314, 1998.

7. Nicolini A, Carpi A and Rossi G: Cytokines in breast cancer. Cytokine Growth Factor Rev 17: 325-337, 2006.

8. Kim R, Emi M, Tanabe K and Arihiro K: Tumor-driven evolution of immunosuppressive networks during malignant progression. Cancer Res 66: 5527-5536, 2006.

9. Balkwill F: Cancer and the chemokine network. Nat Rev Cancer 4: 540-550, 2004.

10. Kato M, Kitayama J, Kazama $\mathrm{S}$ and Nagawa H: Expression pattern of CXC chemokine receptor-4 is correlated with lymph node metastasis in human invasive ductal carcinoma. Breast Cancer Res 5: R144-R150, 2003.

11. Nishizuka I, Ishikawa T, Hamaguchi Y, Kamiyama M, Ichikawa Y, Kadota K, Miki R, Tomaru Y, Mizuno Y, Tominaga N, Yano R, Goto H, Nitanda H, Togo S, Okazaki Y, Hayashizaki Y and Shimada H: Analysis of gene expression involved in brain metastasis from breast cancer using cDNA microarray. Breast Cancer 9: 26-32, 2002.

12. Patrikainen L, Porvari K, Kurkela R, Hirvikoski P, Soini Y and Vihko P: Expression profiling of PC-3 cell line variants and comparison of MIC-1 transcript levels in benign and malignant prostate. Eur J Clin Invest 37: 126-133, 2007.

13. Diallo-Danebrock R, Ting E, Gluz O, Herr A, Mohrmann S, Geddert H, Rody A, Schaefer KL, Baldus SE, Hartmann A, Wild PJ, Burson M, Gabbert HE, Nitz U and Poremba C: Protein expression profiling in high-risk breast cancer patients treated with high-dose or conventional dose-dense chemotherapy. Clin Cancer Res 13: 488-497, 2007.
14. Kim TS, Jung MY, Cho D and Cohen EP: Prolongation of the survival of breast cancer-bearing mice immunized with GMCSF-secreting syngeneic/allogeneic fibroblasts transfected with a cDNA expression library from breast cancer cells. Vaccine 24 : 6564-6573, 2006.

15. Song JH, Choi CH, Yeom HJ, Hwang SY and Kim TS: Monitoring the gene expression profiles of doxorubicin-resistant acute myelocytic leukemia cells by DNA microarray analysis. Life Sci 79: 193-202, 2006.

16. Kim SH, Song JH, Choi BG, Kim HJ and Kim TS: Chemical modification of santonin into a diacetoxy acetal form confers the ability to induce differentiation of human promyelocytic leukemia cells via the down-regulation of NF- $\mathrm{kB}$ DNA binding activity. $\mathrm{J}$ Biol Chem 281: 13117-13125, 2006.

17. Ye ZB, Ma T, Li H, Jin XL and Xu HM: Expression and significance of intratumoral interleukin-12 and interleukin-18 in human gastric carcinoma. World J Gastroenterol 13: 1747-1751, 2007.

18. Okamura H, Tsutsi H, Komatsu T, Yutsudo M, Hakura A, Tanimoto T, Torigoe K, Okura T, Nukada Y, Hattori K, Akita K, Namba M, Tanabe F, Konishi K, Fukuda S and Kurimoto M: Cloning of a new cytokine that induces IFN- $\gamma$ production by $\mathrm{T}$ cells. Nature 378: 88-91, 1995.

19. Vidal-Vanaclocha F, Mendoza L, Telleria N, Salado C, Valcárcel M, Gallot N, Carrascal T, Egilegor E, Beaskoetxea J and Dinarello CA: Clinical and experimental approaches to the pathophysiology of interleukin-18 in cancer progression. Cancer Metastasis Rev 25: 417-434, 2006.

20. Kim KE, Song H, Kim TS, Yoon D, Kim CW, Bang SI, Hur DY, Park $\mathrm{H}$ and Cho DH: Interleukin-18 is a critical factor for vascular endothelial growth factor-enhanced migration in human gastric cancer cell lines. Oncogene 26: 1468-1476, 2007.

21. Park CC, Morel JC, Amin MA, Connors MA, Harlow LA and Koch AE: Evidence of IL-18 as a novel angiogenic mediator. J Immunol 167: 1644-1653, 2001.

22. Chandrasekar B, Mummidi S, Mahimainathan L, Patel DN, Bailey SR, Imam SZ, Greene WC and Valente AJ: Interleukin18-induced human coronary artery smooth muscle cell migration is dependent on NF-кB- and AP-1-mediated matrix metalloproteinase- 9 expression and is inhibited by atorvastatin. J Biol Chem 281: 15099-15109, 2006.

23. Zhang B, Wu KF, Cao ZY, Rao Q, Ma XT, Zheng GG and Li G: IL-18 increases invasiveness of HL-60 myeloid leukemia cells: up-regulation of matrix metalloproteinases-9 (MMP-9) expression. Leuk Res 28: 91-95, 2004.

24. Cho D, Song H, Kim YM, Houh D, Hur DY, Park H, Yoon D, Pyun KH, Lee WJ, Kurimoto M, Kim YB, Kim YS and Choi I: Endogenous interleukin-18 modulates immune escape of murine melanoma cells by regulating the expression of Fas ligand and reactive oxygen intermediates. Cancer Res 60: 2703-2709, 2000.

25. Yoon-DY, Cho YS, Park JW, Kim SH and Kim JW: Upregulation of reactive oxygen species (ROS) and resistance to Fas-mediated apoptosis in the C33A cervical cancer cell line transfected with IL-18 receptor. Clin Chem Lab Med 42: 499-506, 2004.

26. Connett JM, Badri L, Giordano TJ, Connett WC and Doherty GM: Interferon regulatory factor 1 (IRF-1) and IRF-2 expression in breast cancer tissue microarrays. J Interferon Cytokine Res 25: 587-594, 2005.

27. Muraoka-Cook RS, Dumont N and Arteaga CL: Dual role of transforming growth factor beta in mammary tumorigenesis and metastatic progression. Clin Cancer Res 11: 937s-943s, 2005

28. Müller A, Homey B, Soto H, Ge N, Catron D, Buchanan ME, McClanahan T, Murphy E, Yuan W, Wagner SN, Barrera JL, Mohar A, Verástegui E and Zlotnik A: Involvement of chemokine receptors in breast cancer metastasis. Nature 410: 50-56, 2001.

29. Koizumi K, Hojo S, Akashi T, Yasumoto K and Saiki I: Chemokine receptors in cancer metastasis and cancer cell-derived chemokines in host immune response. Cancer Sci 98: 1652-1658, 2007.

30. Addison CL, Arenberg DA, Morris SB, Xue YY, Burdick MD, Mulligan MS, Iannettoni MD and Strieter RM: The CXC chemokine, monokine induced by interferon-gamma, inhibits non-small cell lung carcinoma tumor growth and metastasis. Hum Gene Ther 11: 247-261, 2000 